\title{
Diversity of Immunoglobulin Light Chain Usage in the Human Immune Response to Haemophilus influenzae Type b Capsular Polysaccharide
}

\author{
ELISABETH E. ADDERSON, PENELOPE G. SHACKELFORD, ANTHONY QUINN, \\ PATRICIA M. WILSON, AND WILLIAM L. CARROLL \\ Department of Pediatrics and the Eccles Program in Human Molecular Biologv and Genetics, University of \\ Utah, Salt Lake City, Utah 841]2 [E.E.A., W.L.C.]; Department of Pediatrics, Washington University School of \\ Medicine, St. Louis, Missouri 63110 [P.G.S., P.M.W.]; and the Department of Microbiology, \\ University of Oklahoma, Oklahoma City, Oklahoma 73104 [A.Q.]
}

\begin{abstract}
The response to the capsular polysaccharide of Haemophilus influenzae type b (Hib PS) has been used to determine the molecular basis of antibody gene diversity in humans. In contrast to the relatively restricted nature of anti-Hib PS heavy-chain variable region gene expression, a variety of light-chain variable region genes may encode this antibody $(\mathrm{Ab})$ response. Light-chain variable region gene usage appears to determine the expression of certain Ab idiotypes and fine antigen specificity. To further define the role of light-chain variable region gene usage in important anti-Hib PS Ab subgroups, we have cloned and sequenced a number of immunoglobulin light-chain variable region genes (IgVL) from human monoclonal $\operatorname{IgA}$ anti-Hib PS Ab generated in response to Hib PS-protein conjugate vaccines. Three of these $A b$ are encoded by unusual variable segments. One $\kappa-\mathrm{Ab}$ is encoded by the "predominant" $V_{K}$ II A2 germline gene but, in contrast to a previously reported A2-encoded IgVL sequence, differs from the A2 germline sequence. The IgVL sequence of a second $\mathrm{Ab}$ is the only sequence of a $\kappa-A b$ that cross-reacts with the structurally related antigen Escherichia coli $\mathrm{K100}$ polysaccharide reported to date. This IgVL is encoded by a $V_{K}$ IIIsegment most closely homologous to the Humbv328/L16 germline gene, whereas previous reports suggested $V_{K}$ IIIencoded anti-Hib PS Ab might be exclusively encoded by the germline gene Humbv325/A27. A $\lambda-\mathrm{Ab}$, also crossreactive with $\mathrm{K} 100$ polysaccharide, is encoded by a V $\lambda$ III family member, in contrast to our previous report of four $\lambda$-Ab with similar antigen specificity that appeared to be encoded by a single V $\lambda$ VII-gene family member. Each of the three $\mathrm{Ab}$ reported here contain an arginine codon at the VJ joint, indicating an important role in antigen binding. Our data indicate, in marked contrast to the restricted nature of the heavy-chain anti-Hib PS repertoire, a much greater diversity in light-chain variable gene segment usage. (Pediatr Res 33: 307-311, 1993)
\end{abstract}

\section{Abbreviations}

Hib PS, Haemophilus influenzae type b capsular polysaccharide

$\operatorname{IgVL}$, Ig light-chain variable region gene

Received for rapid publication September 21, 1992; accepted November 16 1992.

Correspondence and reprint requests: Dr. William L Carroll, University of Utah, Program in Human Molecular Biology and Genetics, Building 533, Room 3260, Salt Lake City, UT 84112.

Supported by the Medical Research Council of Canada (E.E.A.), grant R01A119350 from the National Institutes of Health, and a Basil O'Connor Starter Scholar Research Award (W.L.C.).

\author{
Ab, antibody \\ PCR, polymerase chain reaction \\ $\mathrm{V}$, light-chain Ig variable segment \\ $\mathrm{J}$, light-chain Ig joining segment \\ FR, framework region \\ CDR, complementarity-determining region
}

K100 PS, Escherichia coli K100 capsular polysaccharide

We have used the human immune response to Hib PS as a model to examine the molecular basis of antibody diversity and antibody-antigen interaction $(1,2)$. Previous studies have shown heavy-chain variable region gene usage in this immune response to be restricted, with preferential use of both certain VH3 heavychain variable segments and VDJ joints (unpublished manuscript). In contrast, at least nine $V_{\kappa}$ and $V \lambda$ segments may encode anti-Hib PS Ab (2-5). However, two important subgroups of anti-Hib PS Ab have been identified. First, the immune response of most subjects immunized with Hib PS vaccine is quantitatively dominated by $\mathrm{Ab}$ expressing a cross-reactive idiotype, Hibid-1, which is associated with a $V_{\kappa}$ II gene family member, A2 (2, 4, $6)$. We, and others have previously shown that these A2-encoded $\mathrm{Ab}$ appear to be unmutated, even if antigen is presented as a protein-conjugated polysaccharide $(2,4)$. The complete nucleotide sequence of one such $\mathrm{VH}$ segment is completely identical to the A2 germline sequence (2), and partial amino acid sequences of several other $\mathrm{A} 2$-encoded $\mathrm{Ab}$ are also identical or nearly identical to the translated A2 gene sequence (4). The absence of somatic mutation and the apparent restriction of important antiHib PS light chains to single germline elements would place great dependence for effective immunity on the germline endowment of the individual. Absence or polymorphism of these important germline elements may result in the lack of expression of these $\mathrm{Ab}$ in an individual's anti-Hib PS repertoire. The lack of somatic mutation would make it impossible for less effective VL germline genes to acquire increased avidity through amino acid replacement substitutions.

A second portion of the anti-Hib PS Ab response cross-reacts with the structurally similar antigen K100 PS $(3,7)$. It has been postulated that this cross-reactivity may contribute to the acquisition of "natural" anti-Hib PS Ab by young children $(7,8)$. Anti-Hib PS Ab that cross-react with K100 PS may be encoded by $V_{\kappa} I, V_{k} I I I$, and $V \lambda$ genes $(2,3)$. We previously suggested the cross-reactivity of $\lambda$-anti-Hib PS Ab was mediated by a single V $\lambda$ VII germline gene (2). To date, no nucleic acid or amino acid sequence of a $k-\mathrm{Ab}$ cross-reacting with $\mathrm{K} 100$ PS has been reported. 
To further examine the role of light-chain variable region gene usage in this immune response, we have obtained nucleotide sequences of three additional IgVL genes encoding monoclonal anti-Hib PS Ab. Each of these IgVL genes is atypical. These findings suggest that the human IgVL response to Hib PS may be more complex than previously noted.

\section{MATERIALS AND METHODS}

Generation of hybridoma cell lines secreting human monoclonal anti-Hib PS Ab has been previously described $(2,6)$. Briefly, healthy volunteers were immunized with either Hib PS conjugated to diphtheria toxoid (Hib PS-D) (Connaught Laboratories, Swiftwater, PA) or Hib oligosaccharide conjugated to Corynebacterium diphtheriae $\mathrm{CRM}^{197}$ protein (Lederle Laboratories, Wayne, NJ). Seven d after immunization, peripheral blood lymphocytes were harvested and fused to a nonsecreting murine myeloma cell line, yielding heterohybridoma cell lines secreting human MAb specific for Hib PS. Specific anti-Hib PS binding was documented by $\mathrm{Ab}$ binding to ${ }^{125} \mathrm{I}$-labeled antigen in an RIA (9) and by inhibition of binding by $1.25 \mu \mathrm{g} / \mathrm{mL}$ of soluble Hib PS in an ELISA (10). Cross-reactive idiotype expression was measured by the ability of the antiidiotypic Ab Hibid-1 to inhibit Hib PS binding as previously described (6). Cross-reactivity with E. coli K100 PS was assayed by inhibition of binding to Hib PSpolylysine with $100 \mu \mathrm{g} / \mathrm{mL}$ of soluble K100 PS in an ELISA as described (2). IgVL segments were amplified by PCR, using amplification primers and PCR conditions as reported earlier (2), and directly cloned into pCR1000 phagemid vectors (Invitrogen, San Diego, CA). Sequencing of IgVL genes was performed by the dideoxy technique (9). Two to four clones were obtained and sequenced for each IgVL gene.

The most closely homologous germline and rearranged variable segments were identified by comparison of anti-Hib PS IgVL genes to sequences entered into the Genbank database.

\section{RESULTS}

Hybridoma cell lines. Three hybridoma cell lines, obtained from unrelated subjects, were selected for study to examine the structural basis for certain serologic characteristics (expression of

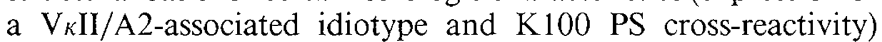
(Table 1). All subjects had detectable anti-Hib PS Ab in preimmunization sera and demonstrated substantial increases in $\mathrm{Ab}$ concentration 1 mo after immunization. Thus, these monoclonal anti-Hib PS Ab are representative of a secondary immune response.

IgVL genes. The Ann2 $\mathrm{V}_{\kappa}$ segment is $98 \%$ homologous (five bp different) to the A2 germline gene at both the nucleic acid and amino acid level and uses a $\mathbf{J}_{K} 1$ segment that differs from the germline sequence by a single nucleotide (Figs. 1 and 2) (4, 15). The Ann 2 nucleic acid sequence differs from our previously reported RC3 $\mathrm{V}_{\kappa}$ segment, which was $100 \%$ homologous to A2, and the Ann2 translated amino acid sequence differs from the previously reported partial amino acid sequences of five A2encoded anti-Hib PS Ab by one or two residues $(2,4)$. The Ann2 VJ joint has an arginine residue at position $95 \mathrm{a}$, as do all A2encoded anti-Hib PS Ab and most other anti-Hib PS Ab described to date (2-4).

LD2 1 is a $\kappa$-Ab using a $V_{\kappa}$ III segment $91.5 \%$ homologous to the germline gene Humbv328/L16 and a $\mathrm{J}_{\kappa} 2$ segment closely homologous to the published germline sequence (Fig. 3) $(13,15)$. The variable segment shares $94.8 \%$ identity with Humbv328/ L16 in FR and $81.9 \%$ in CDR. The translated amino acid sequence of LD21 is $84 \%$ homologous to the Humhv328/L16 germline gene, $91.4 \%$ in FR and $62.5 \%$ in CDR. The LD21 VJ joint also has an arginine residue at position 95 .

The CB20 IgVL gene is encoded by a V $\lambda$ III gene segment

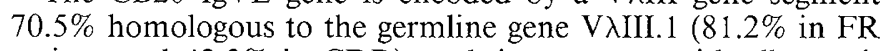
regions and $42.3 \%$ in CDR), and, in common with all $\lambda$-antiHib PS Ab sequenced to date, uses a J $\lambda 2 / 3$ segment (Fig. 4) (2, $14,15)$. All these $\mathrm{J} \lambda$ segments substitute the codon "GTG" for the germline "GTA" at position 92, a silent change likely to reflect a shared genetic polymorphism. The translated CB20 amino acid sequence is $75.4 \%$ homologous to the previously reported VXIII.1 gene, $83.1 \%$ in FR and $55.1 \%$ in CDR. The VJ joint of $\mathrm{CB} 20$, like the two $\kappa-\mathrm{Ab}$, has an arginine codon at position 95 .

\section{DISCUSSION}

To further examine the role of light-chain usage in important subgroups of anti-Hib PS Ab, we have obtained IgVL nucleotide sequences of three human MAb specific for Hib PS.

Reported sequences of A2-encoded anti-Hib PS Ab are remarkable in that they have shown little or no evidence of polymorphism or somatic mutation $(2,3)$. We previously found the nucleic acid sequence of the A2-encoded IgA Ab RC3 VKsegment to be identical to the reported A2 germline gene (2). Furthermore, only one of five partial amino acid sequences of $\mathrm{IgG}$ anti-Hib PS Ab is reported to differ (at a single residue) from the translated amino acid sequence of A2 (4). In contrast, the Ann2 nucleotide sequence differs at five positions from that of A2. These differences may result from three processes: 1 ) the A2 gene may be polymorphic among individuals, 2) Ann2 may be encoded by another germline gene closely related to A2 or 3) somatic mutation of the rearranged A2 gene segment may have occurred. Neither polymorphism of the A2 gene nor the existence of another germline gene more homologous to Ann2 than A2 has been noted $(4,16)$. Although four of five base differences occur in CDR, only one of these differences results in an amino acid substitution. This pattern is not typical of antigen-driven somatic mutation. However, we have recently shown that at least a portion of the heavy-chain anti-Hib PS Ab response is mutated, and these $\mathrm{IgVH}$ genes also did not exhibit significantly elevated ratios of nucleic acid differences resulting in amino acid replace-

Table 1. Hybridoma cell lines*

\begin{tabular}{|c|c|c|c|c|c|c|c|c|}
\hline \multirow[b]{2}{*}{ Hybridoma } & \multirow[b]{2}{*}{ Isotype } & \multirow[b]{2}{*}{ Vaccine } & \multicolumn{2}{|c|}{$\begin{array}{c}\text { Anti-Hib PS } \\
\mathrm{Ab}\end{array}$} & \multirow{2}{*}{$\begin{array}{l}\text { Hibid-1 } \\
\text { expression }\end{array}$} & \multirow[b]{2}{*}{ K100 PS } & \multicolumn{2}{|c|}{ Homologous germline genes } \\
\hline & & & Pre & Post & & & $\mathrm{IgVH}$ & $\operatorname{lgVL}$ \\
\hline Ann2 & $\operatorname{lgAl} / \kappa$ & $\mathrm{Hib} O \mathrm{OC}$ & 1.7 & 110 & + & - & VH3 VH26 (12) & $\mathrm{V}_{\kappa} \mathrm{II} \mathrm{A} 2(4)$ \\
\hline LD2 1 & $\operatorname{IgA} 2 / \kappa$ & Hib PS-D & 0.7 & 58 & - & + & $\mathrm{NK} \dagger$ & VКIII Humhv328/L16 (13) \\
\hline $\mathrm{CB} 20$ & $\operatorname{IgA} 2 / \lambda$ & $\mathrm{Hib} \mathrm{OC}$ & 21.0 & 75 & - & + & VH3 LSG6.1末 & V $\lambda$ III III. I (14) \\
\hline
\end{tabular}

* Columns show name of hybridoma cell line, heavy-chain isotype and light-chain constant region usage, vaccine formulation (Hib PS-D is Haemophilus influenzae type b polysaccharide conjugated to diphtheria toxoid; Hib OC is Haemophilus influenzae type b oligosaccharide conjugated to $\mathrm{CRM}^{197}$ protein), subject's serum anti-Hib PS Ab concentration immediately before and 1 mo postimmunization, expression of the $\mathrm{V}_{K} \mathrm{II} / \mathrm{A} 2-$ associated cross-reactive idiotype Hibid-1, cross-reactivity of Ab with K100 PS, and closest germline $\mathrm{VH}$ and $\mathrm{V}_{K} / \lambda$ genes identified. Numbers in parentheses are reference numbers.

$\dagger$ NK, not known.

\$Unpublished manuscript. 


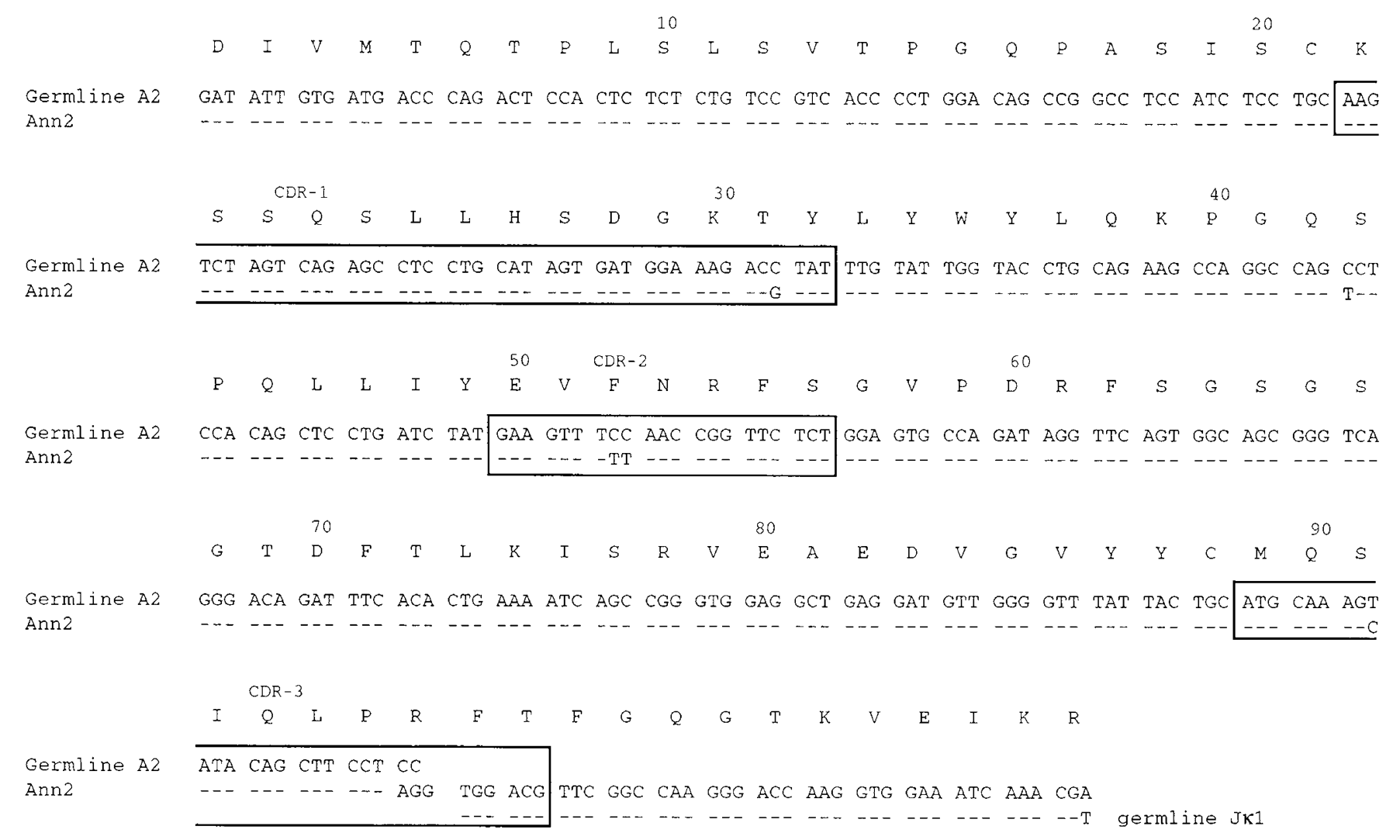

Fig. 1. Nucleotide sequence of the human anti-Hib PS Ab Ann2 IgVL gene. Shown for comparison are the nucleotide sequences of the germline $V_{K}$ II gene A2 (4) and the germline $J_{K} 1$ segment (15). Also shown is the translated amino acid sequence of Ann2. This sequence has been submitted to the Genbank database.

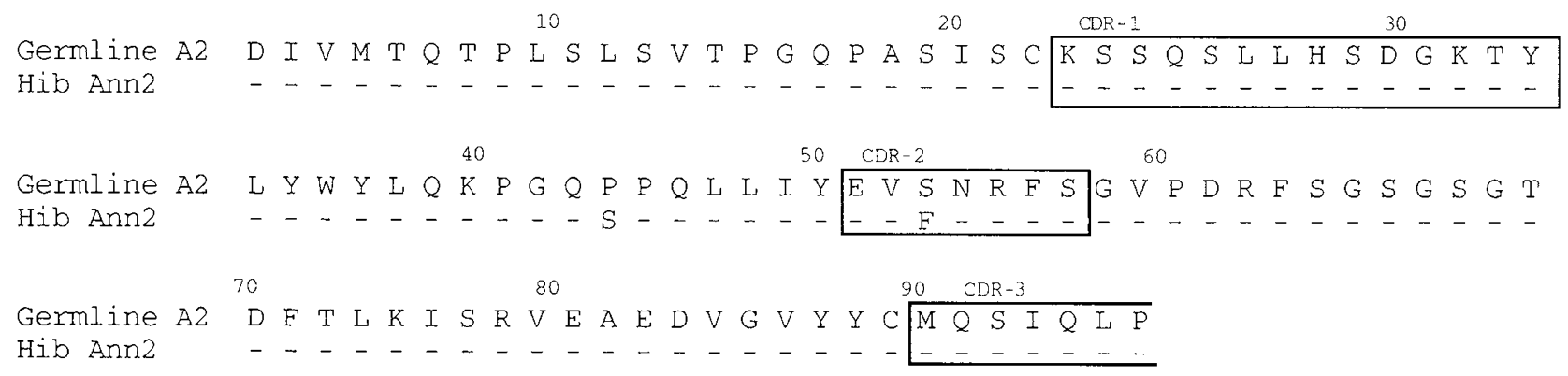

Fig. 2. Translated amino acid sequence of Ann2. Shown for comparison is the translated amino acid sequence of the germline $\mathrm{V}_{\kappa} \mathrm{II}$ gene $\mathrm{A} 2$.

ments to "silent" changes (unpublished manuscript). The associated VH gene of the Ann2 hybridoma is $96 \%$ homologous to the closest known VH3 germline gene (unpublished manuscript); however, without definitive identification of the parental germline gene, we cannot be certain these differences are due to somatic mutation. No correlation between heavy-chain isotype or vaccine formulation and sequence differences from $\mathrm{A} 2$ is obvious in the small number of $\mathrm{Ab}$ reported to date. It will be necessary to obtain nucleotide sequences from additional A2encoded anti-Hib PS Ab and independently isolate germline A2 genes from different individuals to examine these issues.

Partial amino acid sequences of four $\mathrm{V}_{K}$ III anti-Hib PS $\mathrm{Ab}$ obtained from subjects immunized with either plain Hib PS or Hib PS-D vaccine suggested $V_{\kappa}$ III-encoded $A b$ might be encoded exclusively by the germline gene Humhv325/A27 (5). The LD21 $\mathrm{V}_{\kappa}$ segment, however, is more closely homologous to the Humhv328/L16 germline gene and is likely to be encoded by this or a closely related gene. Clearly, a larger number of subjects and $\mathrm{Ab}$ must be studied to establish the frequency and importance of expression of uncommon Ab clonotypes such as LD21.

It has been suggested that $\mathrm{Ab} V \lambda$ segments may be divided into families and subfamilies on the basis of "invariant" amino acids and nucleic acid sequence homology, with homology from subgroup to subgroup $<75 \%$ and within subgroups $>76 \%$ (14). The CB20 V $\lambda$ segment appears to be a member of the V $\lambda$ III gene family, lacking only an invariant valine (substituted for by Ile) at position 47 . The most homologous germline sequence to the $\mathrm{CB} 20 \mathrm{~V} \lambda$ segment described to date is the V $\lambda$ IIIC gene V $\lambda$ III.1. However these gene segments share only $75.4 \%$ identity (14). Although homology between V $\lambda$ III. 1 and CB20 is considerably greater in $\mathrm{FR}$ than in CDR regions (81.2 versus $42.3 \%$ ), the ratio of nucleic acid differences that result in amino acid replacements to silent changes is low $(<2: 1)$, suggesting differences between these segments are not a result of somatic mutation. Rather, the CB20 gene is likely to be encoded by another V $\lambda$ III germline gene. The CB20 V $\lambda$ segment is $78.6 \%$ homologous to the V $\lambda$ IIIB

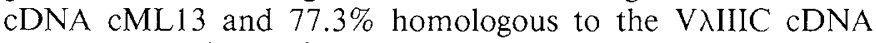
cML23; thus, its subfamily assignment is not clear (14). This overlap of subfamilies has not been generally observed. For example, in a large series of $\mathrm{V} \lambda$ genes described by Combriato and Klobeck (14), the homology of V $\lambda$ IIIC subfamily members ranged from 91.8 to $98.8 \%$, and two V $\lambda$ IIIA members were 
Humkv 328

Hib LD21

Humkv328

Hib LD21

Humhv328

Hib LD21

Humhv 328

Hib LD21

Humhv 328

Hib LD2 1

$\begin{array}{lllllllllllllllllllllllllllllll} & E & I & V & M & T & Q & S & P & A & T & L & S & V & S & P & G & E & R & V & T & L & S\end{array}$ GAA ATA GTG ATG ACG CAG TCT CCA GCC ACC CTG TCT GTG TCT CCA GGG GAA AGA GCC ACC CTC TCC - _... - - - - -

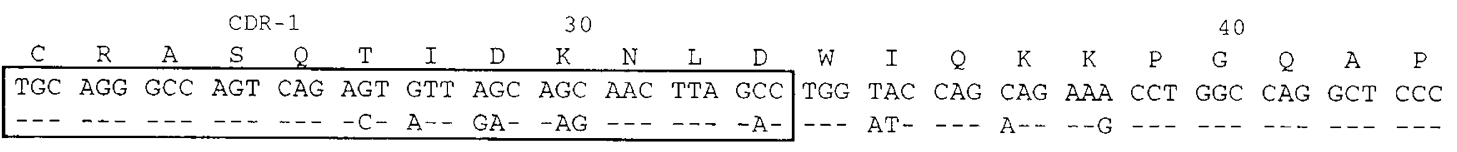

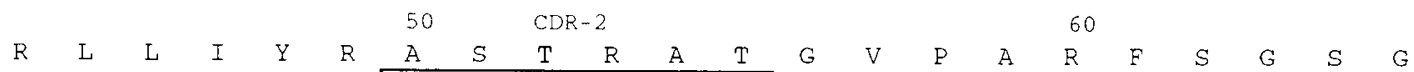
AGG CTC CTC ATC TAT GGT GCA TCC ACC AGG GCC ACT GGC ATC CCA GCC AGG TTC AGT GGC AGT GGG

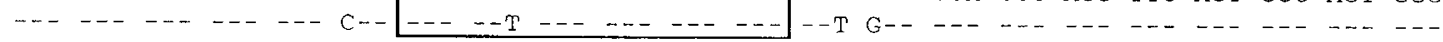

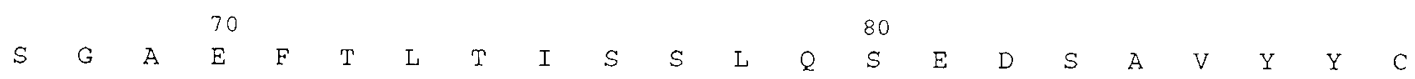
TCT GGG ACA GAG TTC ACT CTC ACC ATC AGC AGC CTG CAG TCT GAA GAT TTT GCA GTT TAT TAC TGT

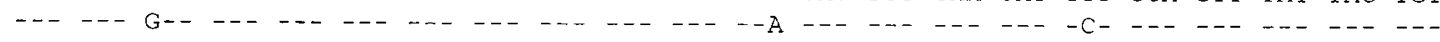

\begin{tabular}{|c|c|c|c|c|c|c|c|c|c|c|c|c|c|c|c|c|c|c|}
\hline & 90 & & $\mathrm{CDR}-$ & & & & & & & & & & & & & & & \\
\hline L & $Q$ & $\mathrm{H}$ & $\mathrm{S}$ & $F$ & $\mathrm{~W}$ & $\mathrm{R}$ & $\mathrm{T}$ & $F$ & G & $Q$ & $G$ & $\mathrm{~T}$ & $\mathrm{~N}$ & L & $E$ & I & K & \\
\hline AG & CAG & TAT & $\mathrm{AAT}$ & AAC & TGG & $\mathrm{CC}$ & & & & & & & & & & & & \\
\hline$T-$ & --- & C-D & $-G-$ & TT- & --- & $\begin{array}{l}-G I \\
T A C\end{array}$ & $\begin{array}{l}\mathrm{ACT} \\
--\end{array}$ & TTT & $\begin{array}{c}\text { GGC } \\
---\end{array}$ & $\begin{array}{c}\mathrm{CAG} \\
---\end{array}$ & $\begin{array}{l}\text { GGG } \\
-\end{array}$ & $\begin{array}{l}\text { ACC } \\
---\end{array}$ & $\begin{array}{l}\mathrm{AAC} \\
--\mathrm{G}\end{array}$ & $\begin{array}{c}\text { CTG } \\
\ldots\end{array}$ & $\begin{array}{c}\text { GAG } \\
---\end{array}$ & $\begin{array}{l}\text { ATC } \\
-\end{array}$ & $\begin{array}{l}\text { AAA } \\
-\end{array}$ & \\
\hline
\end{tabular}

$\mathrm{J} \kappa 2$

Fig. 3. Nucleotide sequence of the human anti-Hib PS Ab LD21 Ab IgVL gene. Shown for comparison are the nucleotide sequences of the germline $V_{\kappa}$ III gene Humhv328/L16 (13) and the germline $J_{\kappa} 2$ segment (15). Also shown is the translated amino acid sequence of LD21. This sequence has been submitted to the Genbank database.

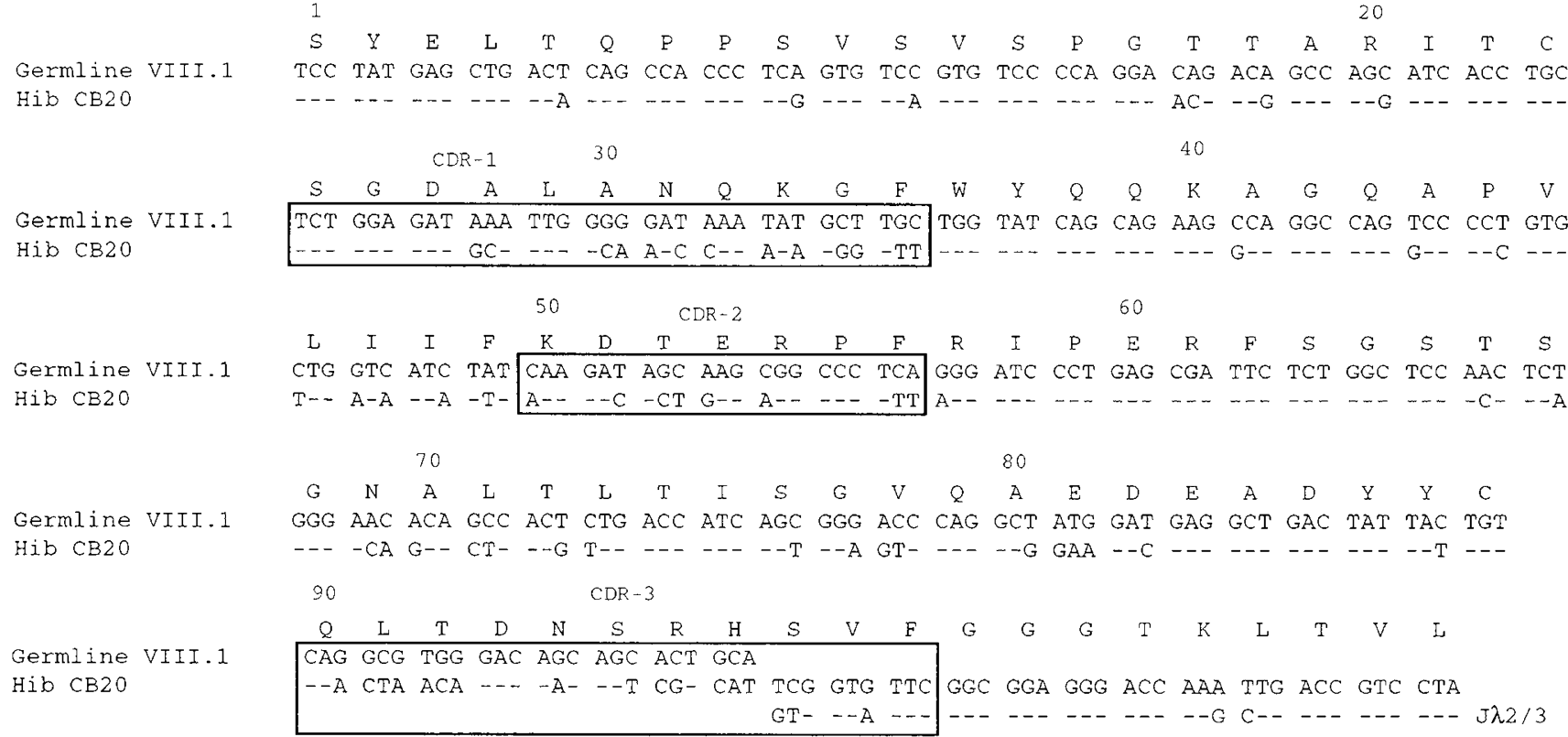

Fig. 4. Nucleotide sequence of the human anti-Hib PS Ab CB20 Ab IgVL gene. Shown for comparison are the nucleotide sequences of the V $\lambda I I I$ gene III. 1 (14) and the germline $\mathrm{J} \lambda 2 / 3$ segment (15). Also shown is the translated amino acid sequence of CB20. This sequence has been submitted to the Genbank database.

$96.5 \%$ homologous (14). The definitions of these subgroups are arbitrary, however, and as increasing numbers of $V \lambda$ segments are identified other genes sharing overlapping homology with two or more closely related subgroups are likely to be identified.

Anti-Hib PS Ab cross-reactive with K100 PS express V $\lambda, V_{K} I$, or $V_{K}$ III segments, but not the "predominant" $V_{\kappa} I I / A 2$ segment $(2,3)$. Consistent with these findings, the Ann2 Ab, encoded by the A2 germline gene, does not bind K100 PS. We previously obtained sequences of four $\mathrm{V} \lambda$-expressing anti-Hib PS Ab which cross-react with K100 PS. All of these segments appeared to derive from a single germline V $\lambda$ VII gene (2). CB20, however, is encoded by a V $\lambda$ III gene family member, suggesting that a more heterogeneous group of $\mathrm{V} \lambda$ genes may encode K100 PS cross- reactive $A b$ than previously supposed. $L D 21$ is the first nucleic acid sequence of a $\mathrm{V}_{\kappa}$-encoded anti-Hib PS Ab that cross-reacts with K100 PS. Studies of additional MAb or purified serum Ab will demonstrate whether K100 PS cross-reactivity of this subgroup is restricted to Humhv328/L16-encoded Ab or whether other $V_{\kappa}$ III genes, such as Humhv325/A27, may be used.

CDR-3 of each of these three hybridoma IgVL genes are notable for the presence of an arginine codon at position 95 or 96. The $5^{\prime}$ proximal nucleotides of the $\mathrm{J}_{K} \mathrm{I}$ gene are "TGG" and the $3^{\prime}$ proximal nucleotides of $\mathrm{A} 2$ are "CC." Thus, the codon "AGG" at the Ann2 VJ must have been created by the uncommon event of "N" addition (of at least a single "G"), as previously described in the A2-encoded anti-Hib PS IgVL gene RC3 (2). 
The LD21 $\mathrm{V}_{\kappa}$ segment is less similar to a known germline gene. The arginine codon may, therefore, be encoded by an unknown germline gene or may result from either somatic mutation or " $N$ " addition. The Arg-95 codon of CB20 may be encoded by the V $\lambda$ segment or by "N" addition. Ten of 11 anti-Hib PS IgVL genes we have identified to date feature an arginine residue at the $\mathrm{VJ}$ joint, implying that this amino acid is very important in antigen binding.

We have obtained nucleotide sequences of IgVL genes from three monoclonal human anti-Hib PS Ab representative of serum antibodies with important serologic or antigen-binding characteristics. Each of these genes uses IgVL gene segments that have not previously been described, suggesting that the diversity of the total anti-Hib PS $\mathrm{Ab}$ repertoire and that of important subgroups of $\mathrm{Ab}$ may be greater than appreciated. It has been hypothesized that poor response to Hib PS vaccine or infection might result from the absence of one or more of the germline Ig gene segments critical to this immune response (4). The identification of an increasingly large number of IgVL gene segments that may be used to encode anti-Hib PS Ab suggests that this postulate is relevant only to the much more restricted heavychain variable region gene usage.

These new $\mathrm{Ab}$ clonotypes may be quantitatively minor constituents of the serum anti-Hib PS Ab response, inasmuch as partial amino acid sequences of somewhat larger numbers of $\mathrm{Ab}$ have not previously detected similar IgVL usage. Interpretation of these data is confounded by the use of different vaccine formulations, the selection of $\mathrm{Ab}$ for study at different time points in the immune response, and the selection of $\mathrm{Ab}$ of $\mathrm{a}$ particular heavy-chain isotype. Additional studies are required to examine the expression of $\mathrm{IgVL}$ segments in response to different vaccine formulations and to define the structural basis of antigen specificity.

Acknowledgments. The authors thank Dr. Michael A. Simmons for his support, Drs. Alexander H. Lucas and Dan M. Granoff for providing the antiidiotypic antibody Hibid-1 and for helpful discussion, and Venita Boelloeni for performing assays for Hibid-1 expression.

\section{REFERENCES}

1. Adderson EE, Shackelford PG, Quinn A, Carroll WL 1991 Restricted Ig heavy chain $\mathrm{V}$ gene usage in the human antibody response to Haemophilus influenzae type b capsular polysaccharide. J Immunol 147:1667-1674
2. Adderson EE, Shackelford PG, Insel RA, Quinn A, Wilson PM, Carroll WL 1992 Immunoglobulin light chain variable region gene sequences for human antibodies to Haemophilus influenzae type $\mathrm{b}$ capsular polysaccharide are dominated by a limited number of $V_{K}$ and $V \lambda$ segment and $V J$ combinations. J Clin Invest 89:729-738

3. Scott MG, Tarrand JJ, Crimmins DL, McCourt DW, Seigel NR, Smith CE, Nahm MH 1989 Clonal characterization of the human IgG antibody repertoire to Haemophilus influenzae type b polysaccharide II. IgG antibodies contain VH genes from a single VH family and VL genes from at least four VL families. J Immunol 143:293-298

4. Scott MG, Crimmins DL, McCourt DW, Zocher I, Theibe R, Zachau HG, Nahm MH 1989 Clonal characterization of the human IgG antibody response to Haemophilus influenzae type b polysaccharide. III. A single $V_{K} I I$ gene and one of several $\mathrm{J}_{K}$ genes are joined by an invariant arginine to form the most common $L$ chain $V$ region. J Immunol 143:4110-4116

5. Scott MG, Crimmins DL, McCourt DW, Chung G, Schable KF, Thiebs R, Quenzel E-M, Zachau HG 1991 Clonal characterization of the human IgG antibody repertoire to Haemophilus influenzae type b polysaccharide. IV. The less frequently expressed VL are heterogenous. J Immunol 147:40074013

6. Lucas AH, Granoff DM 1990 A major crossreactive idiotype associated with human antibodies to the Haemophilus influenzae b polysaccharide. Expression in relation to age and immunoglobulin $G$ subclass. J Clin Invest 85:1158-1166

7. Insel RA, Anderson PW 1982 Cross-reactivity with Escherichia coli $\mathrm{K} 100$ in the human serum anticapsular antibody response to Haemophilus influenzae type b. J Immunol 128:1267-1270

8. Schneerson R, Robbins JB 1975 Induction of serum Haemophilus influenzae type $\mathrm{b}$ capsular polysaccharide antibodies in adult volunteers fed crossreactive Escherichia coli 075:K100:H5. N Engl J Med 292:1093-1096

9. Granoff DM, Shackelford PG, Pandey JP, Boies EG 1986 Antibody response to Haemophilus influenzae type b polysaccharide vaccine in relation to the $\mathrm{Km}(1)$ and $\mathrm{G} 2 \mathrm{~m}(23)$ immunoglobulin allotypes. J Infect Dis 154:257-264

10. Shackelford PG, Granoff DM, Nelso SJ, Scott MJ, Smith DS, Nahm MH 1987 Subclass distribution of human antibodies to Haemophilus influenzae type b capsular polysaccharide. J Immunol 138:587-592

11. Sanger FS, Nicklen S, Coulson AR 1977 DNA sequencing with chain terminating inhibitors. Proc Natl Acad Sci USA 79:5463-5467

12. Chen PP, Liu M, Sinha S, Carson DA 1988 A 16/6 idiotype positive anti-DNA antibody is encoded by a conserved VH gene with no somatic mutation. Arthritis Rheum 31:1429-1431

13. Chen PP, Robbins DL, Jirik FR, Kipps TJ, Carson DA 1987 Isolation and characterization of a light-chain variable region gene for human rheumatoid factors. J Exp Med 166:1900-1905

14. Combriato G, Klobeck $H-G 1991 \mathrm{~V} \lambda$ and $J \lambda-C \lambda$ gene segments of the human immunoglobulin $\lambda$ light-chain locus are separated by $14 \mathrm{~kb}$ and rearranged by a deletion mechanism. Eur J Immunol 21:1513-1522

15. Kabat EA, Wu TT, Reid-Miller M, Perry HM, Gottesman KS 1987 Sequences of Proteins of Immunological Interest. US Public Health Service, Bethesda, MD

16. Lautner-Rieske A, Huber C, Meindl A, Pargent W, Schable KF, Thiebe R, Zocher I, Zachau HG 1992 The human immunoglobulin $k$ locus. Characterization of the duplicated A regions. Eur J Immunol 22:1023-1029 